\title{
Oil, water, ice and light
}

\section{LEIV K. SYDNES}

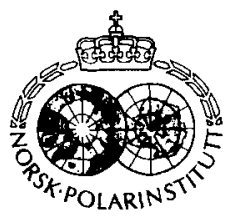

Sydnes, L. K. 1991: Oil, water, ice and light. Pp. 609-618 in Sakshaug, E., Hopkins, C.C.E. \& Øritsland, N.A. (eds.): Proceedings of the Pro Mare Symposium on Polar Marine Ecology, Trondheim, 12-16 May 1990. Polar Research 10(2)

The behaviour and ultimate effect and fate of oil in the marine environment in the polar region depend on a large number of factors. From a chemical point of view the most important ones to consider are the intrinsic chemical properties of the oil, the consequences of oil/water interactions, the influence of ice on physical and chemical processes, and the interactions between oil and light when the influx of solar energy shows great seasonal changes. This paper reviews the main aspects of these issues.

Leiv K. Sydnes, Department of Chemistry, University of Troms $\emptyset$, N-9000 Troms $\emptyset$. Norway.

For decades the search for oil and natural gas was a land-based, commercial activity carried out in tropical and temperate regions. In more recent years the search for new petroleum resources has moved into more desolate areas like the Arctic. With the growth of activity in this region, in general through shipping traffic and in particular through oil exploration (including drilling and testing), the amount of petroleum entering the marine environment has been increasing. It has therefore become necessary to acquire an understanding of the complex physical, chemical, and biological interactions of oil with the biotic and abiotic components of the Arctic environment. The purpose of this paper is to discuss some of these interactions from the standpoint of a chemist.

From a chemical point of view the most important factors to consider are the intrinsic chemical properties of the oil, the consequences of oil/ water interactions, the influence of ice on physical and chemical processes, and the interactions between oil and light.

\section{The oil}

Crude oil is an exceedingly complex mixture of organic compounds (oil components) which have been formed by degradation of organic material of biogenic origin under considerable pressure $(60-100 \mathrm{~atm})$ and at elevated temperatures $\left(>65^{\circ} \mathrm{C}\right)$. The structures of several thousand oil components have been elucidated, from the simplest compound, methane, to very complex mol- ecules containing more than 80 carbon atoms. Close to $90 \%$ of most crude oils are pure hydrocarbons, but in extreme cases this amount may be less than $50 \%$. The reason for this large variation is that the composition of an oil depends on the type of biogenic material from which the oil has been formed. Particularly sensitive is the relative amount of saturated hydrocarbons, aromatic hydrocarbons, and asphaltenes/resins; the gross composition of a crude oil is therefore often described by the content of these three groups of compounds. The saturated hydrocarbons consist of normal and branched alkanes (paraffins) and cycloalkanes (naphthenes); the aromatic hydrocarbons include pure aromatics, cycloalkanoaromatic compounds, and unsaturated sulfur compounds (mainly thiophene derivatives); the asphaltene and resin fraction comprises high molecular weight polycyclic compounds which have aromatic character, contain $\mathrm{N}, \mathrm{S}$ and $\mathrm{O}$ atoms, are rather polar, and are insoluble in condensed propane.

Generally, the saturated hydrocarbons predominate considerably in most crude oils and may amount to nearly $90 \%$ in rare cases (Table 1). The main exceptions to this rule are immature oils and oils that, for one reason or another, have suffered degradation. The aromatic hydrocarbons are most often the second most important group of oil constituents. The majority of known oils contain $20-30 \%$ of such compounds, but higher and lower values are not rare (Table 1). Finally, the total amount of resins and asphaltenes in a crude oil is very much affected by the thermal history of the biogenic material during oil gen- 
Table 1 . The composition of some crude oils in percent by weight. ${ }^{a b}$

\begin{tabular}{ccccc}
\hline Oil \# & Sulfur & Saturated HC & Aromatic HC & Asphalthenes/Resins \\
\hline 1 & 0.12 & 70.4 & 19.4 & 10.2 \\
2 & 0.15 & 64.6 & 22.6 & 12.8 \\
3 & 0.02 & 89.0 & 9.8 & 1.2 \\
4 & 0.07 & 58.2 & 35.8 & 6.2 \\
5 & 0.17 & 58.4 & 20.6 & 21.0 \\
6 & 2.07 & 57.2 & 28.6 & 14.2 \\
7 & 0.38 & 42.4 & 21.2 & 36.4 \\
8 & 0.05 & 78.6 & 16.2 & 5.2 \\
9 & 0.38 & 49.1 & 25.1 & 25.8 \\
\hline
\end{tabular}

${ }^{a}$ The data for oil \#6 are taken from Tissot \& Welte 1984: all other data are taken from Hughes et al. $1985 .{ }^{b}$ HC $=$ hydrocarbons.

eration and values ranging from 0 to $40 \%$ have been reported. The content is usually high in degraded oils and immature oils found in shallow depositional environments; due to increased thermal cracking the content decreases with increasing accumulation depth.

The "average" physical and chemical properties of the three groups of oil components discussed above are significantly different, and the development of an oil spill in the marine environment will therefore to a large extent be oil-dependent. This is always a fundamental problem when preparing environmental protection in new oil exploration areas since the properties and nature of the oil accumulated in the sediment are unknown prior to drilling, detection, and testing. The only viable way of handling an oil spill under such circumstances is to use sound judgement based on past experience with other spills. In this perspective, three types of chemical species found in oil are of particular relevance, regardless of the environmental conditions. Firstly, most crude oils contain an abundance of hydrocarbons which are volatile, and at the same time rather soluble, in aqueous solutions (Table 2). In open waters the largest fraction of these compounds will evaporate directly, but some will dissolve or be suspended in the water column and be lost by subsequent volatilisation (Mackay \& Wells 1983). In regions covered with ice, on the other hand, evaporation will be partly or completely prevented; as a result the volatile compounds will to a much larger extent dissolve in the aqueous phase or penetrate into the ice (see below), causing more extensive damage to the marine biota. Most oils also contain a fair amount of surface-active materials (surfactants), either as single compounds or as aggregates. The latter are mainly found in the
Table 2. The solubility of some selected oil components in water at $25^{\circ} \mathrm{C}{ }^{a}$

\begin{tabular}{lc}
\hline Compound & Solubility $/ \mathrm{mg} \mathrm{I}^{-1}$ \\
\hline Butane & 61.4 \\
Hexane & 9.5 \\
Octane & 0.7 \\
Cyclopentanc & 156.0 \\
Cyclohexane & 55.0 \\
Benzene & 1780.0 \\
-Xylene & 175.0 \\
Phenanthrenc & 1.0 \\
Antracene & 0.08 \\
\hline
\end{tabular}

- From McAuliffe 1966, 1980.

asphaltene/resin fraction which is a complex mixture of associated polycyclic aromatic nuclei with alkyl chains of variable length and with a fair number of heteroatoms $(\mathrm{N}, \mathrm{S}, \mathrm{O})$ incorporated (Fig. 1). Depending on the structures, the surfactants are capable of effectively promoting formation of oil-in-water emulsions as well as waterin-oil emulsions ("chocolate mousse") (Mackay \& Zagorski 1982); the latter mixtures can contain up to $80 \%$ water and are very difficult to handle. Finally, crude oil contains a significant amount of unpaired electrons which conceivably (Mill 1989) are able to form aryloxy radicals as well as superoxide:

$$
\begin{aligned}
& \mathrm{Ar} \cdot+\mathrm{O}_{2} \rightarrow \text { ArOO } \\
& \mathrm{O}_{2}+\mathrm{e}^{-} \rightarrow \mathrm{O}_{2}^{-}
\end{aligned}
$$

These species are flexible oxidants under both aqueous and non-aqueous conditions (Sotiriou et al. 1990), and oil components may therefore be oxidised to some extent in the dark as long as oxygen is available. 


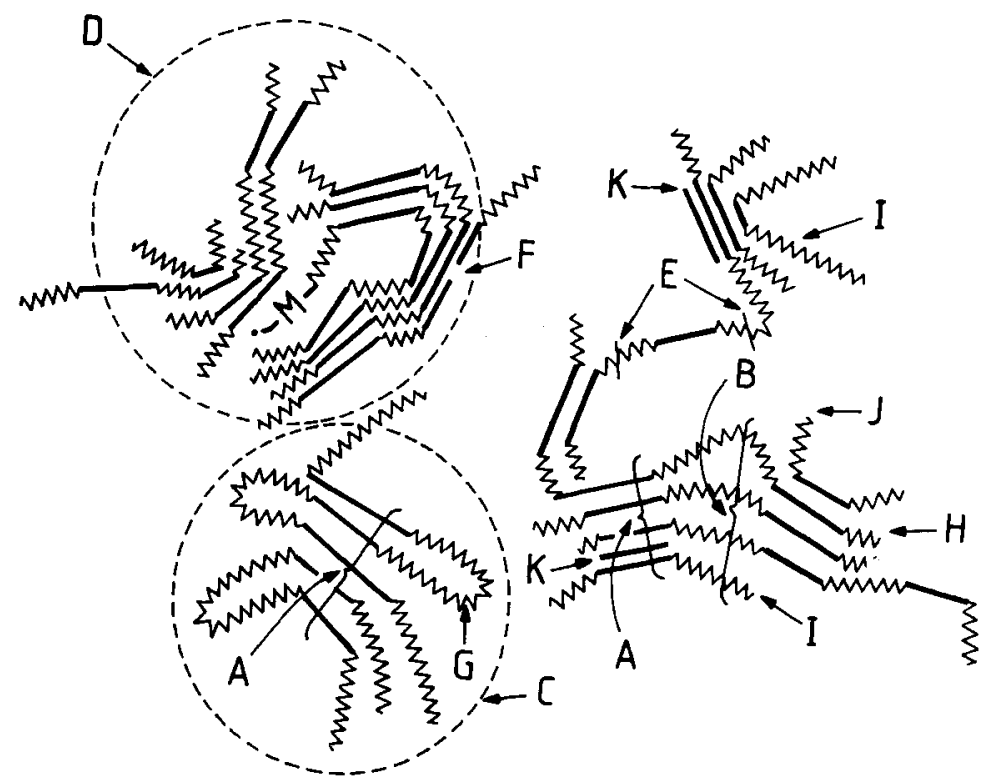

Fig. 1. The structure of an asphaltene assembly precipitated from crude oil. $\mathrm{A}=$ crystallite. $\mathrm{B}=$ chain bundle. $\mathrm{C}=$ particle. $D=$ micelle. $E=$ weak link. $F=$ gap and hole. $G=$ intracluster. $H=$ intercluster. $I=$ resin. $J=$ single layer. $K=$ petroporphyrin. $M=$ metal. Based on Yen 1972 and Tissot \& Welte 1984.

When oil is exposed to significant amounts of sun-light, however, the situation changes. The main reason for this is that asphaltene/resin aggregates and a considerable number of aromatic hydrocarbons commonly found in crude oil will participate in and facilitate the progress of photooxidation reactions (see below).

\section{The water}

During and after an oil spill in a marine environment the seawater participates actively in a number of physical and chemical processes, all of which are intimately connected; it is impossible and misleading to regard these processes as separate events. The interaction between oil and water which results in emulsion formation has already been mentioned; this process is significantly accelerated by the formation of surfaceactive compounds during the photochemical oxidation of oil components (Tjessem \& Aaberg 1983; Tjessem et al. 1983). Another important physical process is oil dispersion which results in the formation of small oil droplets with so little buoyance that they are kept in the water column for quite some time. The rate of dispersion increases tremendously if waves are breaking, and this can create hydrocarbon concentrations, even at considerable depth, at levels which have the potential for toxic effects on marine biota.

The chemical reactions which oil components in the marine environment undergo may depend on the several physical and chemical characteristics of seawater itself. The dependence is negligible for oil in thick patches, but clearly detectable for oil constituents dissolved or dispersed in the water column, or spread out as a thin sheen on the surface.

The dissolved material will either suffer biodegradation (Pilpel 1968) or accumulate on the surface of suspended clay mineral particles and in the interior of micelles (Duinker 1980; Zika 1981). The micelles are formed by the aggregation of natural products present in all seawater, mainly acids, carbohydrates, various humic substances and chlorophyll residues (Williams 1975; Stuermer \& Harvey 1977; Statham \& Williams 1983) (Table 3). The accumulation will generate aqueous microenvironments rich in oil constituents, and this will facilitate absorption of the light available and conceivably induce photochemical transformations of the accumulated oil constituents. The nature of the light penetrating into the water column differs from that of the incident light due to scattering at the surface $(\sim 5 \%)$, 
Table 3. The average contents of organic compounds in seawater ${ }^{a}$

\begin{tabular}{lc}
\hline Component & Concentration $\left(\mathrm{mg} \mathrm{C} \mathrm{m}^{-3}\right)$ \\
\hline Vitamins & 0.0065 \\
Total fatty acids & 5 \\
Urea & 5 \\
Total free sugars & 10 \\
Total carbohydrates & 200 \\
Total free amino acids & 10 \\
Total combined amino acids & 50 \\
Dissolved organic carbon & $500-2000$ \\
\hline
\end{tabular}

"From Williams 1975

backscattering in the water column (5-10\%), and absorption by seawater (Jerlov 1968). Depending on the concentration of absorbing materials, ultraviolet light may reach as deep as $50 \mathrm{~m}$ into the water column (Jerlov 1968), which means that photochemical reactions initiated by UV radiation are not restricted to the surface waters.

The situation is very different for oil constituents spread out on the sea surface. Firstly. the concentration of natural organic material in seawater is much higher in the surface microlayer than in the rest of the water column (Table 4). The exact structures of the molecules comprising this organic microlayer are not known in detail (Hunter \& Liss 1981), but their photophysical and surface-active properties are well established and are known to promote the chemical degradation and the ultimate removal of the oil sheen. Secondly, the amount of solar energy available to oil components on the surface is much higher than in the water column. Finally, oil on the surface is exposed to a number of natural oxidants which are formed photochemically in the surface layer of natural seawater. The steady-state concentrations of these oxidants vary from $10^{-16} \mathrm{~mol}^{-1}$ for the

Table 4. The concentrations of dissolved carbohydrate. measured as carbon. in the microlayer and in subsurface samples."

\begin{tabular}{lcc}
\hline Compounds & $\begin{array}{c}\text { Microlayer } \\
\left(\mathrm{mg} \mathrm{C} \mathrm{m}^{-2}\right)\end{array}$ & $\begin{array}{c}\text { Subsurface } \\
\left(\mathrm{mg} \mathrm{C} \mathrm{m}^{-3}\right)\end{array}$ \\
\hline Monosaccharides & 156 & 81 \\
Polysaccharides & 199 & 99 \\
Total carbohydrates & 355 & 180 \\
DOC $^{h}$ & 1730 & 1100 \\
\hline
\end{tabular}

${ }^{a}$ After Sieburth et al. 1976. ${ }^{h}$ DOC $=$ dissolved organic carbon.
Table 5. The average surface water concentrations of major natural oxidants.

\begin{tabular}{lll}
\hline Oxidant & Concentration/M & \multicolumn{1}{c}{ Reference } \\
\hline${ }^{1} \mathrm{O}_{2}$ & $1 \times 10^{-13}$ & Haag \& Hoigné 1986 \\
$\mathrm{ROO}+\mathrm{RO} \cdot$ & $1 \times 10^{-10}$ & Mill et al. 1980 \\
$\mathrm{HO} \cdot$ & $1 \times 10^{-16}$ & Haag \& Hoigné 1985 \\
& & Russi et al. 1982 \\
${ }^{3} \mathrm{HA}^{a}$ & $2 \times 10^{-13}$ & Haag \& Hoigné 1986 \\
$\mathrm{O}_{2}^{-}$ & $1 \times 10^{-8}$ & Petasne \& Zika 1987 \\
$\mathrm{H}_{2} \mathrm{O}_{2}$ & $1 \times 10^{-8}$ & Zika et al. 1985 \\
\hline
\end{tabular}

${ }^{a} \mathrm{HA}=$ triplet humic acid

hydroxyl radical to $10^{-8} \mathrm{~mol}^{-1}$ for superoxide and hydrogen peroxide (Table 5), but in spite of the low concentrations these oxidants are very effective due to their oxidising power and their wide range of reactivities toward organic molecules of various types.

When oil spreads into a thin sheen on a sea surface, the oil constituents will mix intimately with the chemical species naturally present in the organic microlayer, i.e. surface-active organic compounds and versatile oxidants (see above). If the oil contains largely saturated hydrocarbons and hardly any asphaltenes and resins, participation of the natural chemical species in the organic microlayer is important in the initial phase of the oil degradation. However, after a while numerous oil constituents will have been converted into oxidation products which are both surface active and capable of acting as sensitisers in photochemical reactions (see below) and thus will maintain the degradation process. On the other hand, if the oil comprises a significant amount of aromatic hydrocarbons and/or asphaltenes and resins, the oil sheen itself will contain an abundance of the reactants needed to promote its own photochemical degradation. In any case the degradation products are toxic to a number of marine biota (Larson et al. 1979; Sydnes et al. 1985a).

From what has been discussed in the preceeding paragraphs it is evident that if the water is covered with ice and if the sun is below the horizon, solar energy is unable to reach the water surface. The result is of course that no photochemical reaction can occur; this will put an end to the direct photooxidation of the oil, to the production of natural oxidants, and to subsequent reactions based on these species. 


\section{The ice}

As pointed out previously, photochemical processes in the marine environment may be completely quenched when the solar radiation is filtered by a layer of ice; the degree of quenching depends mainly in the thickness and the quality of the ice. Consequently, oil degradation involving photochemically induced reactions in a system consisting of oil, water, and ice requires that the oil be situated on the ice surface. An oil slick on the surface will interact in various ways with snow and surface ice (Clark \& MacLeod 1977) and also undergo direct photooxidation, but the main effects will be due to the reduction of the reflectivity (albedo) of the snow and ice, causing the oiled area to melt more quickly than nearby unoiled regions. This accelerated melting results in the formation of pools of oil and meltwater which will refreeze and thaw as the temperature varies and which will undergo light-induced degradation similar to that observed in open water.

The interactions in the oil-water-ice system under natural conditions are complex and intimately interconnected, and the system is therefore always far from equilibrium. In similarity to the oil and the water phases, the ice may appear in many different forms which, as experienced in a series of experiments (Sydnes unpubl. data), exhibit rather different behaviour when exposed to oil on a seawater surface. It is outside the scope of this paper to discuss all conceivable forms; only the main types will be mentioned here.
When freezing starts, a slurry of small ice crystals (grease ice) forms rather quickly. When grease ice becomes so thick that circulation within it ceases, the surface freezes into pieces of socalled pancake ice which floats over a layer of grease ice (Martin et al. 1978). Swell and wind will cause the pancakes to oscillate back and forth, and any oil present next to such ice structures will be lifted onto their surface (Martin et al. 1978). This process is very similar to what occurs when thicker ice breaks into small pieces and mixes with oil and water (Fig. 2). The development of such a spill situation is very difficult to predict and also very difficult to handle. The thicker the ice the more difficult is the clean-up operation.

If the ice is thick and its area is large, the development of an oil spill under the ice is more predictable (Fig. 2). When the oil reaches the water-ice interface the oil will spread outward and form pools; the thickness of the oil pools will depend on the evenness of the ice bottom. Because of the considerable friction along the water-ice interface, the oil slick will move with difficulty. If the oil contains a reasonable amount of gas, a gas layer will form between the ice and the oil; this will cause the oil to spread over a larger area. The oil temperature will drop gradually and after a while the oil will be frozen into the growing ice. If the ice is first-year ice, these lenses of encapsulated oil will most likely remain in the ice until spring when the ice is penetrated by brine channels which allow the oil to reach the surface. At the surface the oil will be heated by solar radiation which will induce photooxidation

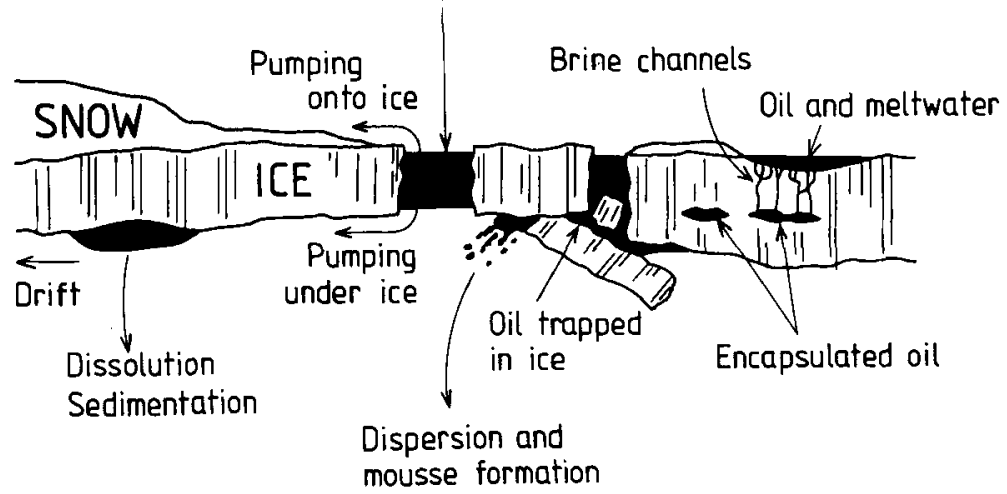

Fig. 2. The behaviour of oil in ice-covered areas. 
and accelerate the formation of meltwater ponds as described earlier.

If the ice is several years old, however, brine channels which reach the surface are not present. In spite of this, the oil will slowly move toward the surface of the ice since new ice is formed at the bottom while sublimation and evaporation take place at the top (Clark \& Finley 1982). How long the oil will take to reach the surface depends of course on the thickness of the ice.

\section{The light}

Sunlight is important for the degradation of various types of chemical compounds in nature (Ross \& Crosby 1975; Zepp et al. 1984). Among these are a large number of oil components, and in order to properly assess the effects of an oil spill in the marine environment it is necessary to keep in mind some of the fundamental aspects of the interactions between light and matter (Turro 1978; Coxon \& Halton 1987).

In order to induce photochemical reactions in a chemical compound the light must interact with electrons in its non-bonding or bonding orbitals and promote one electron to an antibonding molecular orbital of higher energy. The energy needed to perform such an excitation is governed by the relationship $\Delta E=h \nu$ where $\Delta E$ is the energy difference between the orbitals involved and $\nu$ is the frequency of the light. Since the sunlight has been filtered by ozone before reaching the earth, the natural photochemical processes are limited to those reactions that do not require radiation with a wavelength shorter than approxi-

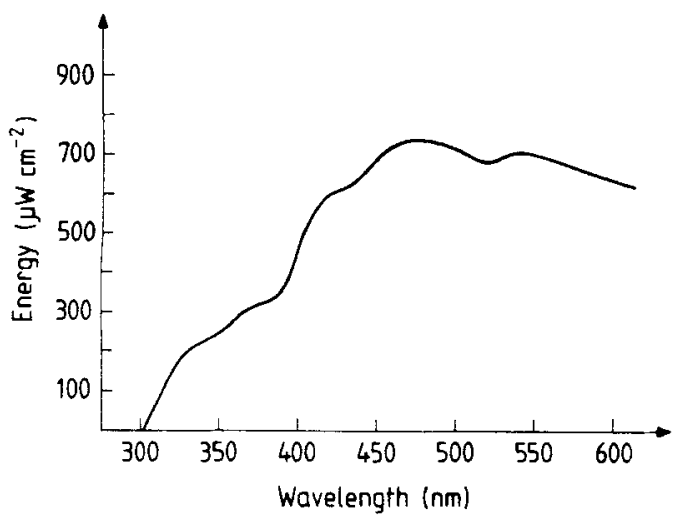

Fig. 3. The energy distribution of solar irradiation at the sea surface. $\sigma^{*}$

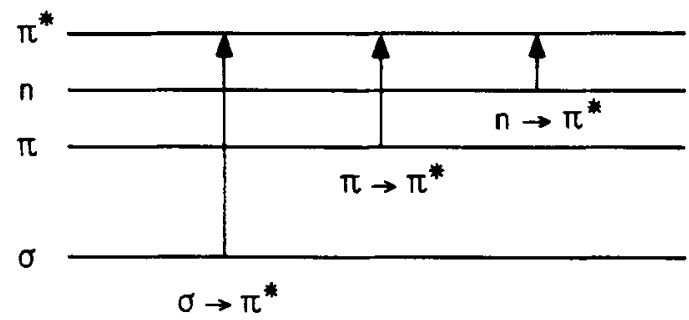

Fig. 4. Electronic excitation processes observed in organic molecules. Non-bonding electrons are denoted $\mathrm{n}$, bonding electrons $\pi$ and $\sigma$ depending on their symmetry, and antibonding electrons $\pi^{*}$ and $\sigma^{*}$ depending on their symmetry.

mately $305 \mathrm{~nm}$ (Fig. 3). As a result, photochemical transformations in nature are restricted to compounds containing molecular orbitals that interact extensively (conjugated systems), i.e. compounds such as aromatic hydrocarbons, unsaturated carbonyl compounds, and unsaturated amines, which are able to undergo $\pi \rightarrow \pi^{*}$ and $n \rightarrow \pi^{*}$ excitations (Fig. 4) when exposed to sunlight.

In general, stable organic compounds have an even number of electrons which are distributed as pairs in molecular orbitals with antiparallel spins (singlet ground state). When light absorption takes place and excitation occurs, an electron is elevated to an antibonding orbital without changing the spin. This leaves the molecule in a singlet excited state, from which the molecule escapes by undergoing physical processes and/or chemical reactions. The physical processes are conveniently summarised in a Jablonski diagram (Fig. 5) where the energy increases along the positive ordinate direction. Most of these processes have no chemical significance, but a notable exception is intersystem crossing (ISC). During ISC spin inversion of the excited electron, generation of unpaired spins, and, consequently, formation of triplet states take place. The ultimate result of these changes is a perturbed molecule which has the characteristics of a radical and whose chemical reactivity is different from that of the singlet analogues. Since ISC generally is an efficient process for aromatic hydrocarbons and ketones, a number of oil components and compounds derived thereof can undergo chemical reactions from both the excited singlet and triplet states. 


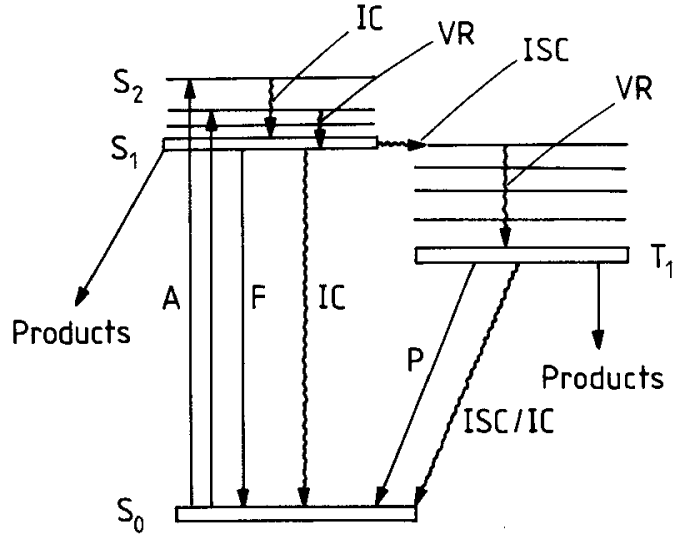

Fig. 5. Jablonski diagram showing the common photophysical processes for organic molecules. $\mathrm{A}=$ absorption. $\mathrm{F}=$ fluorescence. $\mathrm{IC}=$ internal conversion. ISC $=$ intersystem crossing. $\mathbf{P}=$ phosphorescence. $\quad \mathrm{S}=$ singlet. $\quad \mathrm{T}=$ triplet. $\quad \mathrm{VR}=$ vibrational relaxation.

When exposed to sunlight in the marine environment the oil components are intimately mixed with oxygen, and as a result most of the products formed under these conditions are due to photooxidation reactions, albeit fragmentation and polymerisation may also take place. Detailed studies of the photooxidation of selected oil samples and oil components have shown that the reaction is facilitated by the presence of aromatic hydrocarbons, asphaltenes, and resins, and that several reaction pathways may operate at the same time (Hansen 1975; Hansen \& Sydnes 1989; Larson \& Hunt 1978; Sydnes et al. 1985b; Sydnes et al. $1985 \mathrm{c}$ ). It is therefore not surprising that oil components are oxidised much more extensively in the presence than in the absence of oil (Fig. 6).

Three main reactions are probably always involved when photooxidation of oil takes place (Zafiriou 1977):

1. A radical, generated photochemically, $(\mathrm{X} \cdot)$ abstracts a benzylic hydrogen and forms a benzylic radical (Bz:) which can combine with groundstate oxygen $\left({ }^{3} \mathrm{O}_{2}\right)$ and start a chain reaction (Hansen \& Sydnes 1989; Larson et al. 1977; Sydnes et al. 1985b):

$\mathrm{BzH}+\mathrm{X} \cdot \rightarrow \mathrm{Bz} \cdot+\mathrm{XH}$

$\mathrm{Bz} \cdot+{ }^{3} \mathrm{O}_{2} \rightarrow \mathrm{BzOO}$.

$\mathrm{BzOO} \cdot+\mathrm{BzH} / \mathrm{RH} \rightarrow \mathrm{BzOOH}+\mathrm{Bz} \cdot / \mathrm{R} \cdot$

$\mathrm{R} \cdot+{ }^{3} \mathrm{O}_{2} \rightarrow$ ROO

$\mathrm{ROO} \cdot+\mathrm{BzH} / \mathrm{RH} \rightarrow \mathrm{ROOH}+\mathrm{Bz} \cdot / \mathrm{R} \cdot$

$\mathrm{BzOOH} \stackrel{\mathrm{h} \nu \text { or } \Delta}{\longrightarrow}$ Oxidation products + Radicals

$\mathrm{ROOH} \stackrel{\text { hvor } \Delta}{\longrightarrow}$ Oxidation products + Radicals

2. Aromatic compounds in the ground state may undergo complexation with ground-state oxygen and form charge-transfer complexes which generally exhibit a weak, but characteristic absorption maximum above $500 \mathrm{~nm}$. Irradiation at this maximum results in hydroperoxide formation (Aksnes \& Iversen 1983; Sydnes et al. 1985a) (Fig. 7):

\section{$\mathrm{ArH}+{ }^{3} \mathrm{O}_{2} \rightarrow \mathrm{ArH} \cdot \mathrm{O}_{2}$ \\ $\mathrm{ArH} \cdot \mathrm{O}_{2} \stackrel{\mathrm{h} \nu}{\longrightarrow} \mathrm{ArOOH}$}
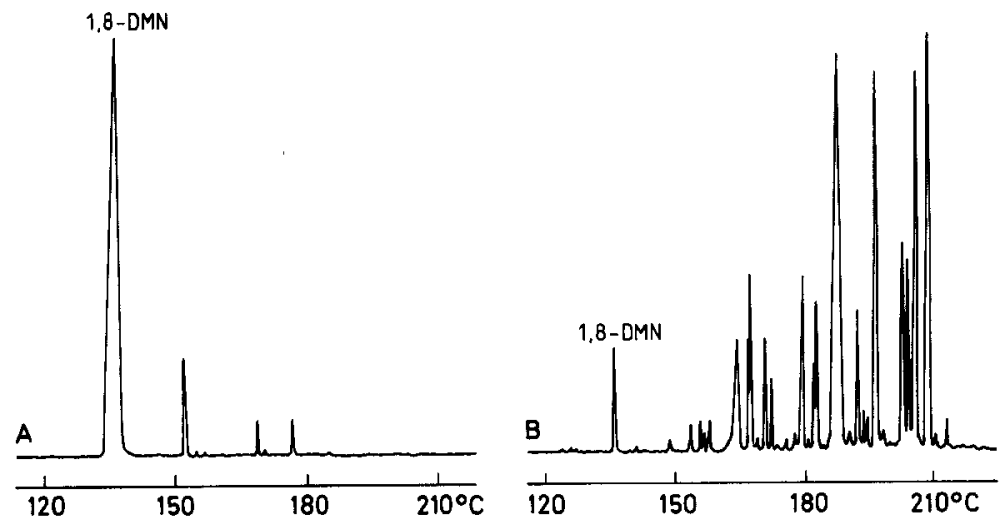

Fig. 6. Gas-chromatographic traces of silylated samples of the organic material dissolved in the aqueous phase during (A) photolysis of 1,8-dimethylnaphthalene (1,8-DMN) on distilled water and (B) photolysis of 1,8-DMN in oil on distilled water (Sydnes et al. 1985c). 


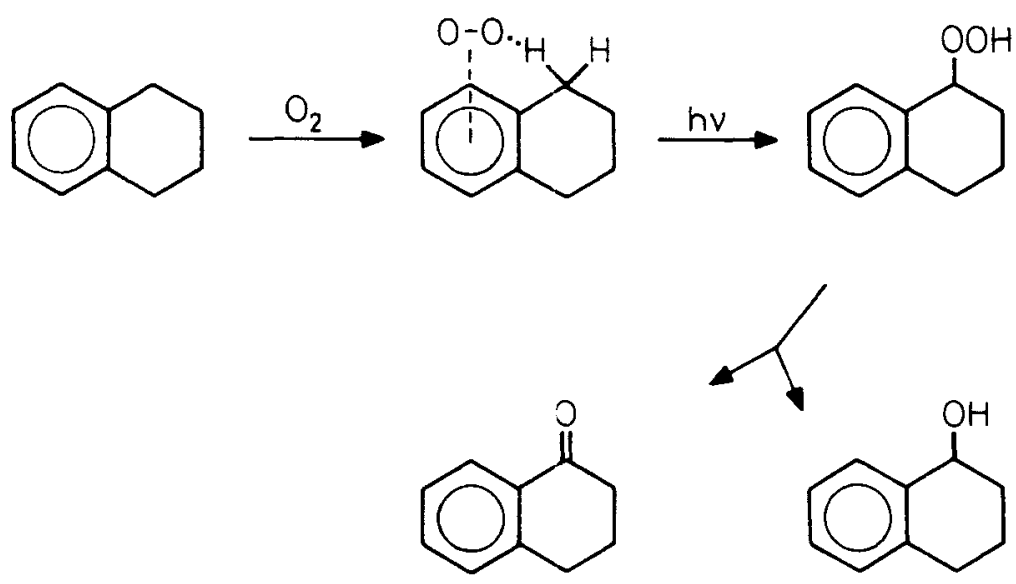

Fig. 7. Photochemical oxidation of tetralin via a tetralin-O2 charge-transfer complex (Aksnes \& Iversen 1983).

3. Triplet-excited organic compounds may also function as sensitisers (S) and transfer the triplet energy to ground-state (triplet) oxygen which simultaneously is excited to singlet oxygen:

$$
\begin{aligned}
& { }^{10} \mathrm{~S} \stackrel{\text { hv }}{\longrightarrow} \text { is } \\
& 1 \mathrm{~S} \stackrel{\text { ISC }}{\longrightarrow}{ }^{3} \mathrm{~S} \\
& { }^{3} \mathrm{~S}+{ }^{3} \mathrm{O}_{2} \rightarrow{ }^{10} \mathrm{~S}+{ }^{1} \mathrm{O}_{2} \\
& { }^{1} \mathrm{O}_{2}+\text { Organic compounds } \rightarrow \text { Oxidation products }
\end{aligned}
$$

Most crude oils contain a number of compounds that can function as sensitisers toward triplet oxygen; polycyclic aromatic compounds, asphaltene constituents, and compounds resulting from their oxidation all possess triplet energy higher than that necessary to excite ${ }^{3} \mathrm{O}_{2}$ to ${ }^{1} \mathrm{O}_{2}\left(92.4 \mathrm{~kJ} \mathrm{~mol}^{-1}\right)$ and are therefore conceivable candidates (Larson \& Hunt 1978; Sydnes et al. 1985c). Furthermore, humic and fulvic acids, which are present in natural seawater, are also well-established producers of singlet oxygen. It is therefore not surprising that oil in the marine environment is chemically modified by ${ }^{1} \mathrm{O}_{2}$ to a considerable extent.

One significant difference between the marine environment in the Arctic regions and those found elsewhere is the enormous seasonal variation in the influx of solar energy. If photooxidation reactions contribute considerably to the degradation of oil. hardly any degradation should take place in the Arctic during the winter, and this is in fact observed (Hansen 1988: Sydnes et al. 1985d). This finding clearly suggests that oil weathering under natural conditions in the Arctic region is considerably influenced by the variation in global radiation.

\section{Closing remarks}

From a chemical point of view the main processes determining the fate of oil in marine environments under Arctic conditions are now reasonably wellunderstood. Ultimately these processes result in detoxification of the oil; but at stages during the degradation, organic compounds that are toxic to marine species are invariably formed. The damage resulting from these compounds and from unchanged oil components in the water phase will to some extent be reduced by oil-degrading bacteria. However, the presence of such bacteria as well as other marine species is limited by a number of factors, particularly the amount of nutrient salts. As a result, assessment of the environmental impact of an oil spill must still be based on a fair amount of guesswork.

There is still a need for more knowledge about the chemical and physical changes that oil undergoes during storage in and migration through multi-year ice (Payne pers. comm.). In order to examine these changes properly it is of course necessary to perform the experiments under conditions as close as possible to those prevailing in nature. Such a simple and fundamental requirement ought to be obvious, but it has often been neglected in the field of environmental chemistry. Consequently, model studies have been carried out under conditions that deviate so much from those found in nature that the results are useless. 
Table 6. Comparison of some experimental parameters in traditional photochemistry and marine photochemistry."

\begin{tabular}{lll}
\hline Parameter & Traditional photochemistry & Marine photochemistry \\
\hline Light wavelength & Stretching below $\sim 305 \mathrm{~nm}$ & Nothing below $\sim 305 \mathrm{~nm}$ \\
Solvent & Non-aqueous & Seawater \\
Number of reactants & One or two & Many, number unknown \\
Concentrations & High enough for direct measurement & Generally far too low to measure easily \\
Phases & One, homogeneous & Several, heterogeneous \\
Oxygen & Usually absent & Always present \\
\hline
\end{tabular}

${ }^{a}$ From Zika 1981.

This has, perhaps in particular, been done in the field of environmental photochemistry, with the result that the literature contains a significant body of data with little or no direct relevance to the natural environment (Zika 1981). The main reason for this awkward situation is conceivably due to the fact that in many cases simulation experiments have been performed under traditional laboratory photochemical conditions which may deviate considerably from those prevailing in nature (Table 6).

Acknowledgements. - Financial support from the Norwegian Research Council for Science and the Humanities (NAVF) through the Norwegian Marine Pollution Research and Monitoring Programme and the Norwegian Research Program for Marine Arctic Ecology (Pro Mare) is most gratefully acknowledged.

\section{References}

Aksnes, G. \& Iversen, A. 1983: Chemosphere 12, 385.

Clark, R. C., Jr. \& Finley, J. S. 1982: Occurrence and impact of petroleum on arctic environments. Pp. 295-341 in Rey, L. (ed.): The Arctic Ocean. The Hydrographic Environment and the Fate of Pollutants. Macmillan Press, London, England.

Clark, Jr., R. C. \& MacLeod, Jr., W. D. 1977: Inputs, transport, mechanisms, and observed concentrations of petroleum in the marine environment. Pp. 91-223 in Malins, D. C. (ed.): Effects of Petroleum on Arctic and Subarctic Marine Environments and Organisms. Academic Press, New York, U.S.A.

Coxon, J. M. \& Halton, B. 1987: Organic Photochemistry. Cambridge University Press, Cambridge, England. 243 pp.

Duinker, J. C. 1980: Suspended matter in estuaries: Adsorption and desorption processes. Pp. 121-151 in Olausson. E. \& Cato, I. (eds.): Chemistry and Biogeochemistry of Estuaries. John Wiley and Sons, Chichester, England

Haag, W. R. \& Hoigné. J. 1985: Photosensitized oxidation in natural water via $\mathrm{OH}$ radicals. Chemosphere 14, 1659-1671.

Haag, W. R. \& Hoigné, J. 1986: Singlet oxygen in surface waters - part III: Steady state concentrations in various types of waters. Environ. Sci. Technol. 20.341-348.

Hansen, H. P. 1975: Photochemical degradation of petroleum hydrocarbon surface films on seawater. Mar. Chem. 3, 183195.
Hansen, S. H. 1988: Some photochemical aspects of oil weathering. Dr. scient. thesis, University of Troms $\emptyset$. Troms $\emptyset$, Norway. $69 \mathrm{pp}$.

Hansen, S. H. \& Sydnes, L. K. 1989: Photochemical oxidation of benzyl alcohol. Acta Chem. Scand. 43, 395-398.

Hughes, W. B., Holba, A. G., Miller, D. E. \& Richardson. J. S. 1985: Geochemistry of greater Ekofisk crude oils. Pp. 7592 in Thomas, B. M., Doré, A. G., Eggen, S. S., Home, P. C. \& Larsen, R. M. (eds.): Petroleum geochemistry in exploration of the Norwegian shelf. Graham and Trotman, London, England.

Hunter, K. A. \& Liss, P. S. 1981: Organic sea surface films. Pp. 259-298 in Duursma, E. K. \& Dawson, R. (eds.): Marine Organic Chemistry: Evolution, Composition. Interactions and Chemistry of Organic Matter in Seawater. Elsevier Scientific Publishing Company, Amsterdam. The Netherlands.

Jerlov, N. G. 1968: Optical Oceanography. Elsevier Scientific Publishing Company, Amsterdam, The Netherlands. 194 pp.

Larson, R. A., Bott, T. L., Hunt, L. L. and Rogenmuser, K. 1979: Photooxidation products of a fuel oil and their antimicrobial activity. Environ. Sci. Technol. 13. 965-969.

Larson, R. A. \& Hunt, L. L. 1978: Photooxidation of a refined petroleum oil: Inhibition by $\beta$-carotene and role of singlet oxygen. Photochem. Photobiol. 28, 553-555.

Larson, R. A., Hunt, L. L. \& Blankenship, D. W. 1977 : Formation of toxic products from a \#2 fuel oil by photooxidation. Environ. Sci. Technol. 11, 492-496.

Mackay, D. \& Wells, P. G. 1983: Effectiveness, behavior and toxicity of dispersants. Pp. 65-71 in Proc. 1983 Oil Spill Conference. Am. Petrol. Inst., Washington. D.C., U.S.A.

Mackay, D. \& Zagorski, W. 1982: Studies of water in oil emulsions. Report EE34, Environment Canada. Ottawa, Canada.

Martin, S., Kauffman, P. \& Welander, P. E. 1978: A laboratory study of the dispersion of crude oil within sea ice grown in a wave field. Pp. 261-287 in Vol. II: Resource DevelopmentProcesses and Problems. Alaska Division, American Association for the Advancement of Science, Fairbanks, Alaska, U.S.A.

McAuliffe, C. 1966: Solubility in water of paraffin, cycloparaffin, olefin, acetylene, cycloolefin and aromatic hydrocarbons. J. Phys. Chem. 70, 1267-1275.

McAuliffe, C. 1980: Oil and gas migration: chemical and physical constraints. Pp. 89-107 in Roberts, W. H. \& Cordell, J. R. (eds.): Problems of petroleum migration. AAPG Studies in Geology No. 10.

Mill, T., Hendry, D. G. \& Richardson, H. 1980: Free-radical oxidants in natural waters. Science $207,886-887$.

Mill, T. 1989: Structure-activity relationships for photooxidation processes in the environment. Environ. Toxicol. Chem. 8. 31-43. 
Petasne, R. G. \& Zika. R. G. 1987: Fate of superoxide in coastal seawater. Nature 325, 516-518.

Pilpel, N. 1968: The natural fate of oil on the sea. Endeavour $100,11-13$.

Ross, R. D. \& Crosby, D. G. 1975: The photooxidation of aldrin in water. Chemosphere 4. 277-282.

Russi, H., Kotzias, D. \& Korte, F. 1982: Photoinduzierte Hydroxylierungsreaktionen organsicher Chemikalien in natürlichen Gewässer. Chemosphere 11. 1041-1048.

Sieburth, J. McN., Willis, P.. Johnson, K. M.. Burney, C. M. Lavoie, D. M. Hinga, K. R. Caron, D. A., French, F. W., Johnson, P. W. \& Davis, P. G. 1976: Dissolved organic matter and heterotrophic microneuston in the surface microlayers of the North Allantic. Science 194, 1415-1418.

Sotiriou. C., Lee, W. \& Giese, R. W. 1990: Superoxide oxidation: A novel route to aromatic 1.2-dicarboxylic acids. J. Org. Chem. 55, 2159-2164.

Statham, P. J. \& Williams. P. J. L. 1983: The automatic determination of dissolved organic carbon. Pp. $380-393$ in Grasshoff, K., Ehrhardt, M. \& Kremling. K. (eds.): Methods of Seawater Analysis; Second, Revised and Extended Edition. Verlag Chemie. Weinheim, Germany.

Stuermer, D. H. \& Harvey, G. R. 1977: The isolation of humic substances and alcohol soluble organic matter from seawater. Deep-Sea Res. 24, 303-309.

Sydnes, L. K., Burkow, I. C., Stene, A. \& Lonning. S. 1985a On the formation of short-lived, toxic, water-soluble compounds during illumination of crude oil on seawater. Marine Environ. Res. 16, 115-126.

Sydnes, L. K., Burkow, I. C. \& Hansen, S. H. 1985b: Photo chemical oxidation of toluene and xylenes. Concurrent formation of products due to photooxygenation and photodimerization. Acta Chem. Scand. B 39,829-835.

Sydnes, L. K. Hansen, S. H. \& Burkow, I. C. 1985c: Factors effecting photooxidation of oil constituents in the marine environment. I. Photochemical transformations of dimethylnaphthalenes in an aqueous environment in the presence and absence of oil. Chemosphere 14. 1043-1055.
Sydnes. L. K., Hemmingsen, T. H., Skare, S., Hansen, S. H. Falk-Pettersen. I.-B., Lønning. S. \& Østgaard. K. 1985d Seasonal variations in weathering and toxicity of crude oil on seawater under arctic conditions. Environ. Sci. Technol. 19 , $1076-1081$

Tissot, B. P. \& Welte, D. H. 1984: Petroleum formation and occurrence. Springer Verlag, Berlin, 2nd ed. 699 pp.

Tjessem, K. \& Aaberg, A. 1983: Photochemical transformation and degradation of petroleum residues in the marine environment. Chemosphere 12, 1373-1394.

Tjessem, K., Kobberstad, O. \& Aaberg, A. 1983: Photochemically induced interactions in Ekofisk crude oil. Chemosphere 12, 1395-1406.

Turro, N. J, 1978: Modern molecular photochemistry. The Benjamin/Cummings Publishing Co. , Inc., Menlo Park, California, USA. $628 \mathrm{pp}$.

Williams, P. J. Le B. 1975: Biological and chemical aspects of dissolved organic material in seawater. Pp. 301-363 in Riley. J. P. \& Skirrow, G. (eds.): Chemical oceanography, 2. Academic Press, London. England.

Yen, T. F. 1972: Present status of the structure of petroleum heavy ends and its significance to various technical applications. Am. Chem. Meet. Reprints F, 102-114.

Zafiriou, O. C. 1977: Marine organic photochemistry previewed. Mar. Chem. 5, 497-522.

Zepp, R. G., Schlotzhauer, P. F., Simmons, M. S., Miller, G. C., Baughman, G. L. \& Wolfe, N. L. 1984: Dynamics of pollutant photoreactions in the hydrosphere. Fresenius $Z$. Anal. Chem. 319, 119-125.

Zika, R. G. 1981: Marine organic photochemistry. Pp. 299-325 in Duursma, E. K. \& Dawson, R. (eds.): Marine Organic Chemistry: Evolution, Composition, Interactions and Chemistry of Organic Matter in Seawater. Elsevier Scientific Publishing Company, Amsterdam. The Netherlands.

Zika, R. G., Moffett, J. W., Petasne, R. G. . Copper. W. J. \& Saltzman, E. R. 1985: Spatial and temporal variations of $\mathrm{H}_{2} \mathrm{O}_{2}$ in Gulf of Mexico water. Geochim. Cosmochim. Acta 49. 1173-1184 